\title{
Preconditioning exposures to the CS: Variation In place of testing'
}

D. CHRIS ANDERSON, DARLENE WOLF, and PATRICK SULLIVAN, University of Notre Dame, Notre Dame, Ind. 46556

One of three groups (Group 1) was given nine 30-sec preconditioning CS (PCS) exposures while bar pressing for food. Half of the remaining groups got the PCS treatment in holding cages. Group 1 and Group 2 then received 12 CS-US pairings elsewhere. Group 3 was given the US only. Group 2 suppressed bar pressing to the $C S$ during testing more than Groups $1(p<.02)$ or $3(p<.01)$ although the PCS-treated half of Group 2 was somewhat less suppressed than the non-PCS half. Group 1 showed more suppression than the other two when all subsequently were tested for running to the $C S$ in an alleyway.

While earlier investigations reported minimal or no effect of preconditioning CS (PCS) exposures on acquisition and extinction of a classically conditioned response (Grant, Hake, Riopelle, \& Kostlan, 1951; Grant, Hake, \& Schneider, 1948; Suboski, DiLollo, \& Gormezano, 1964), more recent studies have indicated that PCS exposures can offset classical learning (Anderson, Merrill, Dexter, \& Alleman, 1968; Carlton \& Vogel, 1967; Lubow, 1965; Lubow \& Moore, 1959). However, even where a PCS effect was obtained, inconsistencies have been reported. For example, Lubow \& Moore (1959) reported an acquisition decrement due to PCS exposure in Experiment 1 , but failed to obtain a reliable effect in Experiment 2 . Moreover, the relatively small differences they reported are to be contrasted with Anderson et al (1968) who, using a modifed CER test procedure, reported no overlap during testing between the suppressed bar-press performance of fear-conditioned Ss who did not receive PCS treatment and the nonsuppressed performance of similarly conditioned Ss who were given PCS exposures.

These apparent inconsistencies prevent an adequate single account of the effect of PCS exposures on classical learning, and suggest that more data is needed for a theoretical reconciliation of the PCS literature. The present experiment thus attempted to provide (a) additional documentation of the effect of PCS exposures on conditioning, (b) an evaluation of PCS effectiveness when given outside the test chamber, and (c) an evaluation of PCS effectiveness when testing was conducted in the same and in a different setting from that where the initial exposures occurred. METHOD

Twenty-four male, 90-day-old, naive albino rats were employed. Two standard operant boxes containing single levers and recessed food trays were employed for training and testing. A 6-ft straight alleyway with a grid floor and food cup located at one end also was employed and used as an alternate test situation. The conditioning chamber, described elsewhere (Anderson et al, 1968), was a cylindrical device (23/4 in. diam $x$ $61 / 2$ in. long) composed of brass rings mounted in plastic railings. The $\mathrm{CS}$ was a $6-\mathrm{V}$ ac buzzer $(25 \mathrm{~dB}$ above a $66-\mathrm{dB}$ ambient background level) and the US was a scrambled $175-\mathrm{V}$ ac shock through a $20 \mathrm{~K}$-ohm series-connected resistor.

All Ss initially were trained to bar press on a VI-30 sec (variable interval) reinforcement schedule. Sessions lasted 15 min per day. The Ss then were trained to run in the alleyway (three $.045-\mathrm{g}$ Noyes pellets per trial). Ten trials per day were given until stable performance was achieved.
Three groups of eight Ss were formed, equated on the basis of total bar presses during the last operant session. Group 1 then received three 30-sec PCS exposures on each of three sessions in the operant chamber. One-half of the remaining two groups received identical PCS treatment in holding cages during the 15-min period before or after bar-press sessions. The physical intensity of the CS was equated for the holding and operant cages.

Twenty-four hours following the last PCS exposure, all Ss were conditioned. The group that received the PCS in the operant chamber and a second group were given 12 forward-conditioning trials [both US intensity and number of conditioning trials were increased over that of Anderson et al (1968) to partially offset the extinction that would occur during testing in the operant box]. The CS lasted $5 \mathrm{sec}$, and overlapped and coterminated with the 2-sec US. The third group received only the US.

On the next day all Ss randomly were presented three 30-sec exposures to the CS while bar-pressing for food. This procedure was repeated on the following day.

On the third day following conditioning all Ss were given five alleyway retraining trials, and food then was removed and the CS placed beneath the food cup. Raising the guillotine door on the next trial occasioned onset of the CS. Total running times were recorded.

\section{RESULTS}

Suppression ratios (SR) and pseudo-SRs were calculated as described by Anderson et al (1968).

Initial exposure to the CS prior to conditioning suppressed bar-press behavior. A comparison of the suppression and pseudosuppression ratios of the PCS and control Ss for the first and last CS presentation produced a reliable $F$ for the interaction effect $(F=6.69$, $\mathrm{df}=2 / 21, \mathrm{p}<.01$ ), indicating greater suppression for the PCS Ss on the initial but not the last PCS exposure.

Figure 1 represents the mean median $S R$ for the three groups. Test presentations of the CS occasioned greatest suppression for the forward-conditioned Ss who did not receive PCS exposures, and no suppression in the US-only controls (there was no difference between the two halves of the US group).

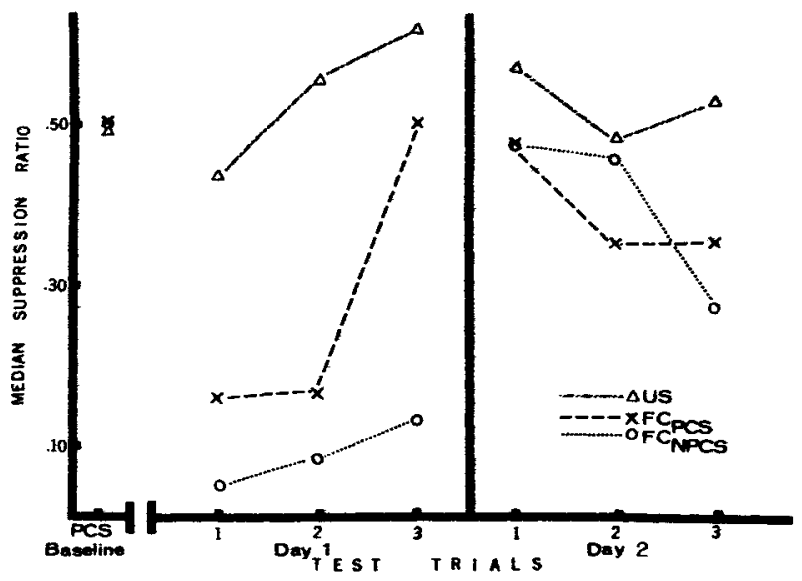

Fig. 1. Mean median suppreseion ratios, by trials and days, for two forward conditioned (FC) and a US-only control groups. 
difference was not statistically significant. In the second experiment, where the female rats were differentially housed for 24 weeks, the activity scores of the isolates were significantly smaller than those of the grouped rats. These results can be explained on the basis of a hypothesis elaborated eisewhere (Archer, in press), that open field activity depends on the effects of the previous housing conditions, and the contrast between these conditions and the environment of the open field. The isolated rats from Experiment 2 experienced low stimulus conditions for a longer period than those from Experiment 1; consequently the change in stimulation involved in placing them in an open field is more likely to elicit fear-responses characterized by "freezing" than in the case of rats isolated for a shorter period of time or ones which have been group-housed for the same period of time.

In the second experiment, the open field scores of the rats from different sized groups also differed significantly, but these differences showed no consistent trend in relation to the group numbers.

In Experiment 2, the open field scores of the isolated female rats were significantly less than those of the grouped animals, whereas in Experiment 3, the open field scores of the isolated and grouped male rats were not significantly different. These results are probably related to differences in the social behavior of male and female rats, perhaps to differences in their aggressive behavior. However, the latter suggestion is only tentative, and will not be elaborated further, as it is discussed more fully elsewhere (Archer, in press).

\section{REFERENCES}

ARCHER, J. E. Effects of population density on behaviour in rodents. In
J. H. Crook (Ed.), Determinants of social behaviour. London and New York: Academic Press, in press.

CHRISTIAN, J. J., \& DAVIS, D. E. Endocrines, behavior and population. Science, $1964,146,1550-1560$.

ESSMAN, W. B. The development of activity differences in ieolated and aggregated mice. Animal Behaviour, 1966, 14, 406-409.

ESSMAN, W. B. Differences in locomotor activity and brain-serotonin metabolism in differentially housed mice. Journal of Comparative \& Physiological Psychology, 1968, 66, 244-246.

MOYER, K. E., \& KORN, J. H. Behrvioral effects of isolation in the rat. Psychonomic Science, 1965, 3, 503-504.

SIEGEL, S. Nonparametric statistics for the behavioral sciences. New York: McGraw-Hill, 1956.

STERN, J. A., WINOKUR, G., EISENSTEIN, A., TAYLOR, R., \& SLY, $M$. The effect of group vs individual housing on behavior and physiological responses to stress in the albino rat. Joumal of Psychosomatic Research, 1960, 4, 185-190.

THIESSEN, D. D. Varying sensitivity of C57B 1/Crgl mice to grouping. Science, 1963, 141, 827-828.

THIESSEN, D. D. Population density and behavior: A review of theoretical and physiological contributions. Texas Reports on Biology and Medicine, 1964, 22, 266-314.

THIESSEN, D. D., ZOLMAN, J. F., \& RODGERS, D. A. Relation between adrenal weight, brain cholinesterase activity and hole-in-thewall behavior of mice under different living conditions. Journal of Comparative \& Physiological Psychology, 1962, 55, 186-190.

WELCH, B. L. Psychophysiological response to the mean level of environmental stimulation: A theory of environmental integration. In D. M. Rioch (Ed.), Medical aspects of stress in the military climate. Washington D.C.: U.S. Govemment Printing Office, 1964. Pp. 39-99.

WELTMAN, A. S., SACKLER, A. M., \& SPARBER, S. B. Endocrine, metabolic and behavioral aspects of isolation stress in female albino mice. Aerospace Medicine, 1966, 37, 804-810.

\section{NOTES}

1. I thank Science Research Council for financial assistance, and Drs. J. H. Crook, J. D. Goss-Custard and D. E. Blackman for critical comments and discussion.

2. Present address: University of Nottingham, England.

\section{(Continued from page 233)}

Initial test suppression for the forward-conditioned group who received PCS exposures was intermediate between the latter two. However, near complete recovery in performance occurred by the third test trial. Although this apparent relative recovery was not revealed in a significant Groups by Trials interaction for Day 1, the overall $F$ for the groups effect was highly reliable $(F=22.00, \mathrm{df}=2 / 21, \mathrm{p}<.001)$. Moreover, a comparison between the overall suppression data for Day 1 between the US-only and forward-conditioned PCS group was reliable $(p<.01)$, as was the difference between the two forward-conditioned groups $(\mathrm{p}<.02)$.

The mean Day-1 SR for the four forward-conditioned Ss who received PCS exposures in holding cages was .14 while for the other four who did not get the PCS treatment it was only $.02(p<.10)$.

Mean total running times on the last retraining trial before testing in the alley were not different between groups $(F<1)$. Mean running times during CS presentation, collapsed over the first three trials of Test Day 1, were $10.18 \mathrm{sec}$ for the forward-conditioned PCS group, $4.65 \mathrm{sec}$ for the forwardconditioned group, and $2.20 \mathrm{sec}$ for controls. This variation in group means was not quite reliable $(F=2.79, p<.10)$.

\section{DISCUSSION}

These data generally supported the more recent finding that PCS exposures can offset manifestation of CER learning. That somewhat greater suppression was observed for the PCS forward-conditioned group over that reported by Anderson et al (1968) probably is due to the considerably more intense US and the two additional conditioning trials that were given in the present investigation.

One trend in the data seems worth comment. The results suggested that the effectiveness of PCS exposures can, in part, be dependent upon the place of PCS presentation. For example, while PCS exposure in the holding cages partially offset test suppression, it was not near as effective as when this preconditioning treatment occurred in the test situation. Moreover, when the forward conditioned Ss who got PCS in the operant box were tested outside the latter situation (i.e., the alleyway), they evinced somewhat more evidence of fear learning than similarly treated, nonPCS Ss. While these latter findings are inconclusive due to marginal reliability values, they nevertheless seem to strengthen the suggestion that the place of preconditioning treatment may be important for demonstration of the PCS effect.

\section{REFERENCES}

ANDERSON, D. C., MERRILL, H. K., DEXTER, W., \& ALLEMAN, $H$. Contextual effects in emotional learning. Proceedings of the American Psychological Association, 1968, 3, 147-148.

CARLTON, P. L., \& VOGEL, J. R. Habituation and conditioning. Journal of Comparative \& Physiological Psychology, 1967, 63, 348-351.

GRANT, D. A., HAKE, H. W., RIOPELlE, A. J., \& KOSTLAN, A. Effects of repeated pre-testing with conditioned stimulus upon extinction of the conditioned eyelid response to light. American Journal of Psy chology, 1951, 54, 247-252.

GRANT, D. A., HAKE, H. W., \& SCHNEIDER, D. E. Effects of repeated pre-testing with conditioned stimulus upon extinction of the conditioned eyelid response. American Journal of Psychology, 1948, 61, 243-246.

LUBOW, R. E. Latent inhibition: Effects of frequency of nonreinforced preexposure of the CS. Journal of Comparative \& Phy siological Psychology, 1965, 60, 454-457.

LUBOW, R. E., \& MOORE, A. U. Latent inhibition: The effect of nonreinforced pre-exposure to the conditional stimulus. Journal of Comparative \& Physiological Psychology, 1959, 52, 415-419.

SUBOSKI, M. D., Dilollo, V., \& GORMEZANO, I. Effects of unpaired preacquisition exposure of CS and UCS on classical conditioning of the nictitating membrane response of the albino rabbit. Psychological Reports, 1964, 15, 571-576. NOTE

1. This research was supported, in part, by Grant MH 15364-01 from the National Institute of Mental Health, USPHS. 